\title{
Research Article \\ Receptivity of Boundary Layer over a Blunt Wedge due to Freestream Pulse Disturbances at Mach 6
}

\author{
Jianqiang Shi, ${ }^{1}$ Xiaojun Tang, ${ }^{1,2}$ Zhenqing Wang, ${ }^{1}$ Mingfang Shi, ${ }^{1}$ and Wei Zhao ${ }^{1}$ \\ ${ }^{1}$ College of Aerospace and Civil Engineering, Harbin Engineering University, Harbin 150001, China \\ ${ }^{2}$ Beijing Spacecrafts, China Academy of Space Technology, Beijing 100094, China
}

Correspondence should be addressed to Xiaojun Tang; xiaojuntang87@sina.com

Received 23 July 2015; Revised 28 February 2016; Accepted 14 March 2016

Academic Editor: Saad A. Ahmed

Copyright (c) 2016 Jianqiang Shi et al. This is an open access article distributed under the Creative Commons Attribution License, which permits unrestricted use, distribution, and reproduction in any medium, provided the original work is properly cited.

\begin{abstract}
Direct numerical simulation (DNS) of a hypersonic compressible flow over a blunt wedge with fast acoustic disturbances in freestream is performed. The receptivity characteristics of boundary layer to freestream pulse acoustic disturbances are numerically investigated at Mach 6, and the frequency effects of freestream pulse wave on boundary layer receptivity are discussed. Results show that there are several main disturbance mode clusters in boundary layer under acoustic pulse wave, and the number of main disturbance clusters decreases along the streamwise. As disturbance wave propagates from upstream to downstream direction, the component of the modes below fundamental frequency decreases, and the component of the modes above second harmonic components increases quickly in general. There are competition and disturbance energy transfer between different boundary layer modes. The nose boundary layer is dominated by the nearby mode of fundamental frequency. The number of the main disturbance mode clusters decreases as the freestream disturbance frequency increases. The frequency range with larger growth narrows along the streamwise. In general, the amplitudes of both fundamental mode and harmonics become larger with the decreasing of freestream disturbance frequency. High frequency freestream disturbance accelerates the decay of disturbance wave in downstream boundary layer.
\end{abstract}

\section{Introduction}

The flow separation, lift, drag, and heat-load on surface are highly dependent on the stare of boundary layer flow when the aircraft flies through the atmosphere. However, laminar and turbulent are usually considered as types of boundary layer flow state [1]. And the aerodynamic forces and aerothermal characteristics for laminar state are significantly different from those for turbulent [2]. Also, it is known from [3] that the aerodynamic heating and forces of the aircraft are significantly affected by laminar-turbulent transition of flow state, which is the process of flow instability. Thus, it is of great importance to simulate the process from laminar condition to turbulent one. It is meaningful for the optimization design of aerodynamic shape, thermal protection, and safety improvement. Given the importance of investigations on boundary layer's stability, a series of experimental and numerical investigations on the subject are conducted [4-8]. At the same time, the research of the stability and transition mechanisms for compressible flow becomes popular in the field of aerodynamics. Compared to incompressible flow, the investigations on the flow characteristics of compressible flow started later, and compressible flow is more complex than incompressible flow [9-11]. Fedorov and Khokhlov [12] confirmed that several unstable modes exist in hypersonic boundary layer. Some modes (mainly the first mode) which correspond to squire mode in incompressible boundary layer are subordinate to viscous unstable modes. Additional inviscid disturbances are called high mode disturbance, and it is believed that the first additional disturbances are the least stable modes for two-dimensional disturbances. Besides, a lot of works on the stability of hypersonic boundary layer were performed by many researchers, including the impact parameter and the theoretical explanation of stability characteristic which are widely studied [13-17]. The receptivity of the boundary layer over a flat plate is studied by Ma and Zhong [13], and 
the effects of different types of freestream disturbances are considered. Layek et al. [14] numerically studied the response of laminar flow in a symmetric sudden expanded channel to wall blowing-suction and found the critical Reynolds number for symmetry breaking of the flow decreased with the increasing values of suction speeds. The effects of nose bluntness on hypersonic boundary layer receptivity and stability over cones are discussed in [15]. Lee et al. [16], based on two different wall temperatures, investigated the effects of wall heating on turbulent boundary layers with temperaturedependent viscosity. Krogstad and Antonia [17] investigated the effects of surface roughness on a turbulent boundary layer by experiment; the turbulent energy production and the turbulent diffusion are significantly affected by rough surfaces. As is shown in previous studies, most of these researches focused on the receptivity of freestream disturbance and wall blowing-suction, effects of nose bluntness on boundary layer stability and wall temperature on disturbance modes evolution in boundary layer, and response of hypersonic boundary layer to roughness wall and turbulence degree in inlet flow. Investigations on this area are usually based on the time period state of unsteady flow under disturbance wave [18]. However, few works were conducted on the interactions between freestream pulse wave and flowfield as well as boundary layer and the stability characteristics of boundary layer for pulse disturbance, whereas flowfield characteristic especially boundary layer state under freestream pulse wave is rather different from that under freestream continuous wave, and the initial generation and development of boundary layer disturbance wave for the former are rather different from the latter. However, the disturbance production and development produced significant effect on boundary layer receptivity [11], which is a significant role in the transition from laminar flow to turbulent. Systematic investigations on the receptivity of boundary layer under freestream pulse are still rare, which not only are helpful to understand the stability characteristic of boundary layer under pulse wave, but also can give a new perspective for boundary layer stability mechanism studies. Therefore, it is necessary to investigate the boundary layer's receptivity under freestream pulse wave. The significant impact of disturbance wave frequency in freestream is confirmed in the investigation on receptivity of hypersonic boundary layer to freestream continuous and weak disturbance wave [19]. It is believed that freestream pulse disturbance frequency had influenced the receptivity of hypersonic boundary layer. Thus, it is necessary to complete much more investigations on the effects of pulse wave frequency in freestream receptivity.

Receptivity is the process that the freestream disturbances react with the shock wave, and then the disturbance entering into the boundary layer leads to the unstable disturbance wave in the boundary layer. To make a survey of the receptivity the theoretical method, the experimental research, and the numerical simulation are all the available tools. The flow stability theory is mainly including linear stability theory and nonlinear stability theory which is mainly used in the theoretical method. The main theoretical analysis tool for small perturbation wave evolution analysis is linear stability theory (LST). When the external disturbance is weak, there will be some linear growth areas with a long distance, and this distance also includes the process of receptivity. Thus, the linear stability theory and the receptivity theory are commonly used to analyze the growth and evolution of small disturbances. That can be used to identify the main components of stability characteristics of boundary layer disturbances [20]. LST is also the basic starting point of the $e^{N}$ method to predict the transition point. But when the flow disturbance is large, nonlinear effects become significant, and the linear stability theory will no longer play a part. The nonlinear stability theory is formed to explain the nonlinear flow transition mechanism. Although the theoretical analysis is reliable and suitable for some typical problems of flow stability, it is of great complexity and can provide only limited flowfield information and its function is limited for broader flow stability problems. The experimental research can provide physical flowfield information in the flow stability investigations. However, it is a huge project to make an experimental research in the aircraft engineering. It will cost a lot of money and energy even in a small experiment and is easily affected by the surroundings [21]. Considering the weak point of the experimental research and the theoretical method a new practical method exists. It is the numerical simulation that dominates in the hypersonic boundary layer stability research. Numerical simulations have high calculation accuracy and waste less energy and the calculation results suit well with the actual situation. DNS is one of the practical methods to simulate the receptivity of the boundary layer. It is of high accuracy and does not need any turbulence model [22].

As is stated above, the unsteady flowfield over a blunt wedge with $8^{\circ}$ half-wedge-angle at Mach 6 under the action of freestream pulse acoustic wave is computed in the present paper. The receptivity characteristics of boundary layer to freestream pulse wave are analyzed, and the effects of pulse wave frequency in freestream on boundary layer receptivity are investigated.

\section{Solution Algorithms}

The flowfield governing equations are the two-dimensional Navier-Stokes (N-S) equations, which can be written as follows:

$$
\frac{\partial \mathbf{U}}{\partial t}+\frac{\partial \mathbf{F}_{i}}{\partial x_{i}}+\frac{\partial \mathbf{F}_{\mathrm{vi}}}{\partial x_{i}}=0 \quad(i=1,2)
$$

The variable $\mathbf{U}$ in the equations is the vectors terms; the variable $\mathbf{F}_{i}$ in the equations is inviscid terms, and the variable $\mathbf{F}_{\mathrm{vi}}$ is viscous flux terms. The variables $\mathbf{U}, \mathbf{F}_{i}$, and $\mathbf{F}_{\mathrm{vi}}$ are given by

$$
\mathbf{U}=\left[\rho, \rho u_{1}, \rho u_{2}, e\right],
$$




$$
\begin{gathered}
\mathbf{F}_{i}=\left[\begin{array}{c}
\rho u_{i} \\
\rho u_{1} u_{i}+P \delta_{1 i} \\
\rho u_{2} u_{i}+P \delta_{2 i} \\
(e+P) u_{i}
\end{array}\right], \\
\mathbf{F}_{\mathrm{vi}}=\left[\begin{array}{c}
0 \\
\tau_{1 i} \\
\tau_{2 i} \\
\tau_{i j} u_{j}+k \frac{\partial T}{\partial x_{i}}
\end{array}\right] .
\end{gathered}
$$

The variables $P, \rho, T, u_{i}, e, \delta_{i j}, \tau_{i j}$, and $k$ in (2) are density, velocity, total energy, Kronecker symbol, shear stress, pressure, and heat conductivity coefficients, respectively. The viscosity coefficient is determined by the Sutherland law; it is shown in

$$
\mu=\mu_{\infty}\left(\frac{T}{T_{\infty}}\right)^{1.5} \frac{T_{\infty}+T_{s}}{T+T_{s}} .
$$

Here, the Sutherland temperature $T_{s}=110.4 \mathrm{~K}$. Under the perfect gas assumption, the pressure is obtained by

$$
P=\rho R T
$$

In the present work, the compressible Navier-Stokes equations are solved by using a high order finite difference method for space discretization and time integration. The convection terms are split into positive convection terms and negative convection terms by Steger-Warming splitting method [23]. Assume the Jacobian is $\mathbf{A}$ and the eigenvalue is $\left\{\lambda_{i}\right\}$, where $i=1,2,3,4,5$. In this case, the inviscid flux terms can be split as follows:

$$
\begin{aligned}
\frac{\partial \mathbf{F}}{\partial x_{i}} & =\frac{\partial \mathbf{F}}{\partial \mathbf{U}} \frac{\partial \mathbf{U}}{\partial x_{i}}=\mathbf{A} \frac{\partial \mathbf{U}}{\partial x_{i}}=\frac{\partial \mathbf{A U}}{\partial x_{i}}=\frac{\partial \mathbf{S} \boldsymbol{\Lambda} \mathbf{S}^{-1} \mathbf{U}}{\partial x_{i}} \\
& =\frac{\partial \mathbf{S}\left(\boldsymbol{\Lambda}^{+}+\boldsymbol{\Lambda}^{-}\right) \mathbf{S}^{-1} \mathbf{U}}{\partial x_{i}} \\
& =\frac{\partial \mathbf{S} \boldsymbol{\Lambda}^{+} \mathbf{S}^{-1} \mathbf{U}}{\partial x_{i}}+\frac{\partial \mathbf{S} \boldsymbol{\Lambda}^{-} \mathbf{S}^{-1} \mathbf{U}}{\partial x_{i}}=\frac{\partial \mathbf{F}^{+}}{\partial x_{i}}+\frac{\partial \mathbf{F}^{-}}{\partial x_{i}}
\end{aligned}
$$

A 5th-order accurate weighted essentially nonoscillatory (WENO) scheme [24] is used for the space discretization of both positive convection terms and negative convection terms:

$$
\begin{aligned}
& \frac{\partial \mathbf{F}^{+}}{\partial x_{i}}=\frac{1}{\Delta x_{i}}\left(\sum_{N=1}^{6} n_{N} \mathbf{F}_{j+4-N}^{-}\right) \\
& \frac{\partial \mathbf{F}^{-}}{\partial x_{i}}=\frac{1}{\Delta x_{i}}\left(\sum_{N=1}^{3} K_{N}\left(\mathbf{F}_{v_{j+N}}-\mathbf{F}_{v_{j-N}}\right)\right) .
\end{aligned}
$$

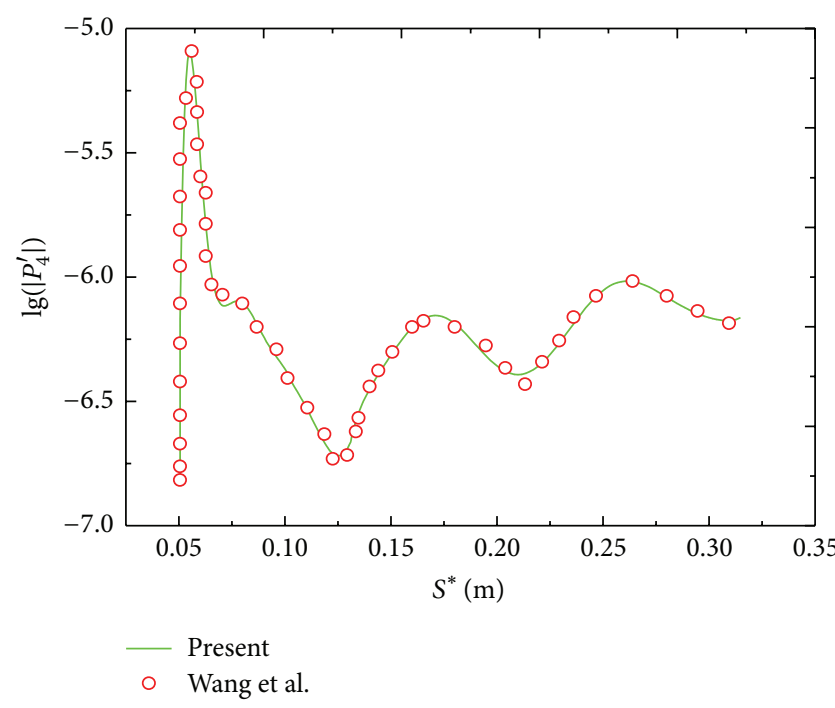

FIgURE 1: The comparison of the pressure disturbance amplitude of the fourth harmonic mode $P_{4}$ development along streamwise $S^{*}$ with Wang et al.s result [32].

A 6th-order center difference scheme [25] is employed for viscous terms space discretion:

$$
\frac{\partial \mathbf{F}_{v}}{\partial x_{i}}=\frac{1}{\Delta x_{i}}\left(\sum_{N=1}^{3} K_{N}\left(\mathbf{F}_{v_{j+N}}-\mathbf{F}_{v_{j-N}}\right)\right) .
$$

Here, the variables $m_{N}, n_{N}$, and $K_{N}$ are weighting coefficient.

A third-order, total variation diminishing (TVD) RungeKutta scheme [26] is introduced to time integration

$$
u^{(i)}=\sum_{k=0}^{3}\left(\alpha_{i k} u^{(k)}+\Delta t \beta_{i k} L\left(u^{(k)}\right)\right) \quad(i=1,2,3) .
$$

In (8), $\Delta t$ is time increment and $\alpha$ and $\beta$ are the weighting coefficient.

These methods are suitable in the flows with discontinuities or high gradient regions. In particular, the high order weighted essentially nonoscillatory (WENO) and the improved WENO methods are widely implemented in the DNS of compressible turbulent flows, in order to keep higher order approximations in smooth regions and to eliminate or suppress oscillatory behavior near the discontinuities [2731]. The solution of the unsteady flowfield can be described as follows: in a given direction, the spatial derivatives at the nodes are approximated by a higher order interpolation and the neighboring nodal values in that direction. The resulting equations are then integrated into time to get the instantaneous parameter values at the point as a function of time. To validate this numerical method, the similar situation of the numerical simulation is performed by the numerical scheme, which is a Mach 8 flow over a $5.3^{\circ}$ half-angle wedge under disturbances wave. Figure 1 shows the comparison of the pressure disturbance amplitude of the fourth harmonic mode $P_{4}$ development along streamwise $S^{*}$ with Wang et al.'s result [32], indicating that the numerical scheme used in this paper is available. 


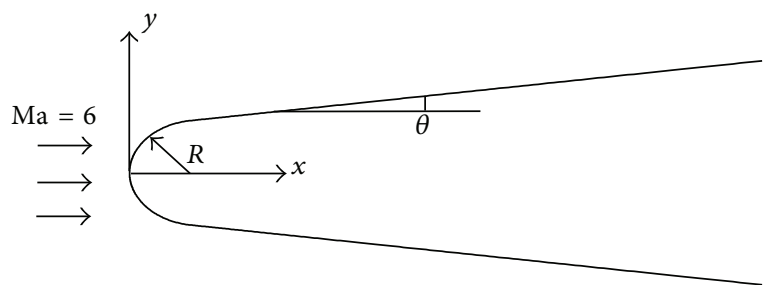

(a) Computational model

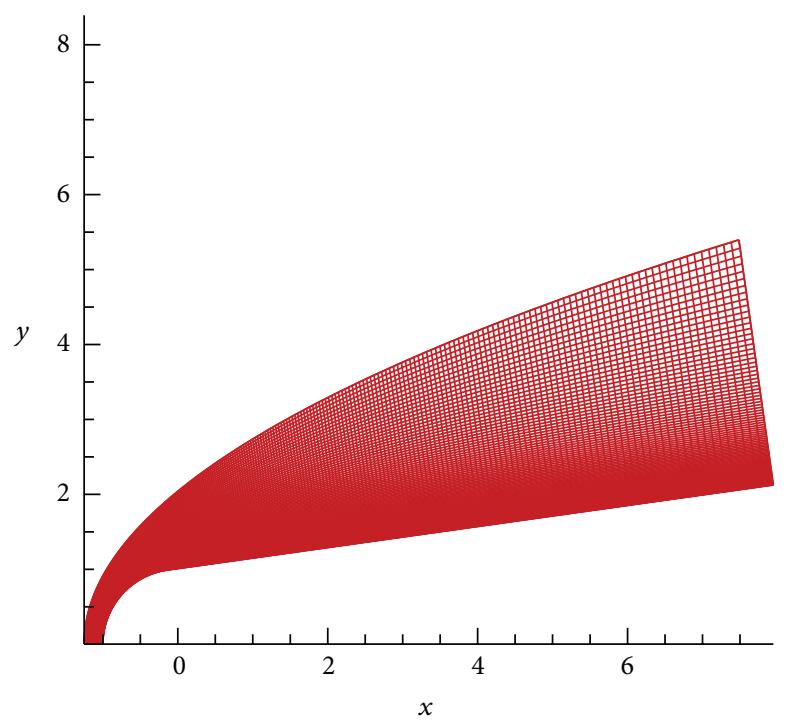

(b) Mesh grid

FIgURE 2: Computational model and mesh grid.

\section{Computational Conditions}

The numerical simulations of hypersonic flow over an $8^{\circ}$ halfangle wedge with blunt nose radius $R=1 \mathrm{~mm}$ are performed at a freestream Mach number of 6.0. Freestream temperature $T_{\infty}=169 \mathrm{~K}$. Angle of attack AOA $=0$ degrees. Wedge angle $\theta=16$ degrees. Reynolds number, $\operatorname{Re}_{n}=\rho_{\infty} R u_{\infty} / \mu_{\infty}$, based on freestream parameters (density $\rho_{\infty}$, velocity $u_{\infty}$, and viscosity coefficient $\mu_{\infty}$ ) and the wedge nose radius, is equal to 10000 . It should be mentioned that subscript “ $\infty$ " denotes freestream condition. Figure 2(a) shows the computational model and Figure 2(b) shows the mesh grid. Using a grid size of $300 \times 120$, the calculations are resolved. The density of mesh grid in this paper matches that in the investigations with similar numerical model conducted by Zhang et al. [19]. A stretching method is used in the wall-normal direction in order to cluster more points inside the boundary layer and nose region. The stretching method used is also employed in the verification simulation of Figure 1. Results show the current results agree well with Wang et al's [32]. The variables density $\rho$, pressure $P$, time $t$, length, and velocity are nondimensionalized by their corresponding reference variables $\rho_{\infty}, \rho_{\infty} u_{\infty} u_{\infty}, R / u_{\infty}, R$, and $u_{\infty}$, respectively. According to the reference variables of density, pressure, time, length, and velocity, the other parameters are also nondimensionalized; for instance, frequency $f$ is nondimensionalized by $u_{\infty} / R$. No-slip, no-penetration, and isothermal wall (wall temperature $T_{w}=500 \mathrm{~K}$ ) conditions are employed on wall surface. Symmetry condition and extrapolation are employed at the $x$-axis $(y=0)$ and the outflow boundary, respectively. The computation procedure contains two steps: first, to compute the steady mean flow and next (at $t=0$ ), to employ fast acoustic disturbance at the upper boundary (freestream boundary) and perform the computations of unsteady flowfield with freestream disturbance. The form of the disturbance employed can be expressed as follows:

$$
\left[\begin{array}{c}
u^{\prime} \\
v^{\prime} \\
p^{\prime} \\
\rho^{\prime}
\end{array}\right]=\left[\begin{array}{c}
A \\
0 \\
\frac{A}{M_{\infty}} \\
A M_{\infty}
\end{array}\right] e^{i\left(k x-\left(F \cdot \operatorname{Re} / 10^{6}\right) t+\pi / 2\right)}
$$

where the variables $A=0.06, k=3.1446 \times 10^{-4}$, Ma $=$ 6.0 , and $t$ are amplitude, wave number, Mach number, and time, respectively. The variables $u^{\prime}, v^{\prime}, p^{\prime}$, and $\rho^{\prime}$ are the disturbance values of velocity along axis $x$, velocity along axis $y$, pressure, and density, respectively. It should be mentioned that superscript " $"$ " denotes the disturbance value of flow variables. The disturbance of flow variables is represented by the variables value of instantaneous flow minus the variables value of the local steady base flow at the same location. Three generalized frequencies $F=50 \pi, 100 \pi$, and $150 \pi$ (dimensionless $f=0.25,0.50$, and 0.75 ) are computed. For pulse wave, the length of time is $1 / 2$ cycle. A fitted coordinate system $s$ using in [19] is employed to represent the distance from the points on the generatrix to the stagnation point. The relationship between $x$ and $s$ is expressed in [19].

\section{Results and Discussion}

4.1. Disturbance Modes in the Blunt Wedge Boundary Layers. To investigate the evolution of disturbance wave in the boundary layer, the instantaneous pressure disturbance in boundary layer for pulse wave $(f=0.25)$ at different surface locations is shown in Figure 3. It is found that when the 

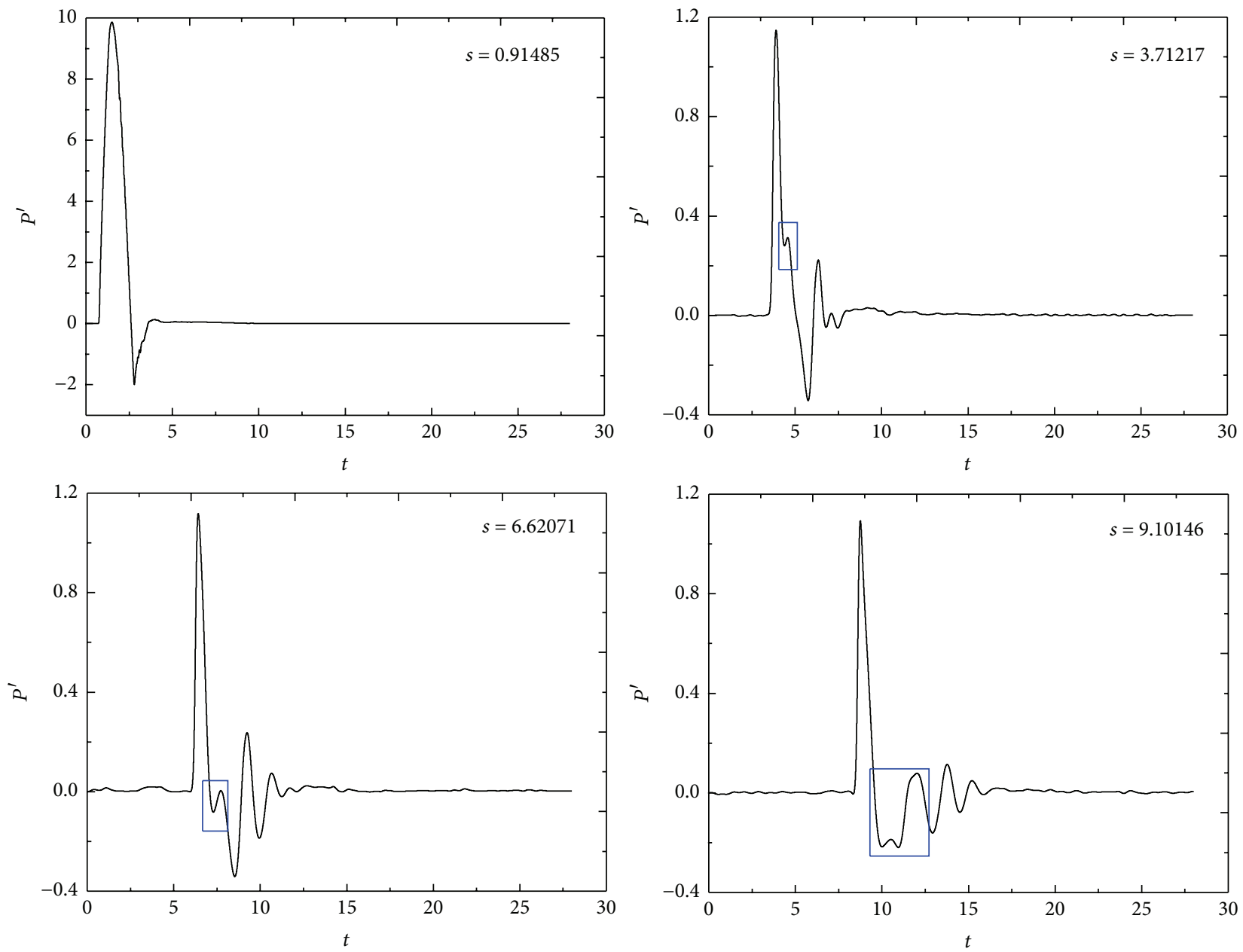

FIGURE 3: Instantaneous pressure disturbance in boundary layer for pulse wave.

fast acoustic wave pulse wave passed through somewhere on the wall, the amplitude of the pressure disturbance $P^{\prime}(x, y, t)$ firstly increases and then decreases, the shape of which is similar to freestream pulse disturbance; when the wave went through the wall completely, the effect still continues and experiences many damped oscillations until the amplitude tends to 0 . It is believed that the damped oscillation is due to the reflection between bow shock wave and wall [18]. It is also found that the pressure disturbance in boundary layer is much larger than that in freestream and the forcing disturbance is enlarged by bow shock. According to the supersonic flow stability theory, the flow parameters such as the pressure, temperature, and density will be significant changes after the shock interference [33]. It is known that the freestream disturbance wave precisely showed the flow parameters fluctuate. Therefore, the bow shock wave has a significant amplification effect on freestream disturbance wave. It is worth mentioning that part of the wave disturbances especially the disturbance waves in the nose area of hypersonic blunt wedge flowfield will be reflected back and forth movement between the wall and the bow shock after the interaction between the bow shock and freestream pulse wave. Every time there was a shock wave reflection, and the disturbance will be amplified once [18]. It is believed that this reciprocal reflex movement has a certain effect on the amplification although there is viscous dissipation during the disturbance waves spreading process. In Liang et al.s investigations $[18,34]$, they gave out similar analysis to present work. Their LST and the DNS results show that the bow shock has a significant amplification effect on freestream small disturbance. Yan's survey [35] explained the research on the characteristics of the first mode and the second wave of instability. The phenomenon indicates that the bow shock has a significant effect on the disturbance wave. These results are consistent with the present results obtained in this paper. The following is worth mentioning. (1) The pressure disturbance in nose boundary layer $(s=0.91485)$ is much larger than that in no-nose boundary layer $(s=6.62071,9.10146)$; that is to say, the amplification effect at nose far outweighs that at nonnose. According to the theory of supersonic flow that free flow pressure disturbance will be magnified under the interference of the bow shock. It is known that in the nose area it is approximately normal shock, but in the no-nose area the corresponding bow shock is oblique shock [32]. Obviously, the normal shock is of greater strength than the oblique shock, so the amplification effect in nose area is 
significantly larger than that in the no-nose area. (2) The pressure disturbance signal form appears to be relatively single upstream $(s=0.91485)$ but got complex downstream $(s=$ $6.62071,9.10146)$. According to the receptivity theory [15], the disturbances react with the shock wave in the head area, and then the disturbance entering into the boundary layer leads to the unstable disturbance wave in the boundary layer [36]. From Figure 3, the disturbance occurs as single formation in the head area. It is because the disturbance wave in the nose boundary layer is mainly the initial disturbances wave which occurs after the interaction between freestream disturbance and the bow shock. However, with the disturbance waves propagating along the streamwise, the repeated reflection between wall and bow shock and the repeated interaction between disturbance wave and boundary layer increase. This complicates the form of disturbance waves. It is obvious that the frequency of disturbance wave in the boundary layer is changed under the complex interaction and reflection. The evolution of unstable disturbance waves in boundary layer plays an important role in determining boundary layer stability [11, 29], so many research works have been done on the evolution of unstable disturbance waves under freestream continuous small disturbance [11, 18, 22, 28]. However, few works are performed on that under pulse wave. Hence, the evolvement of unstable disturbance waves in boundary layer will be analyzed in Figures 3 to 10 .

To analyze the frequency domain signal in boundary layer, Fourier transform is introduced to separate the pressure disturbance signal at different surface locations. Fourier transform can be expressed as follows:

$$
P^{\prime}(x, y, t)=\sum_{n=0}^{N}\left|P_{n}^{\prime}(x, y)\right| e^{i[-n \omega t+\phi n(x, y)]} .
$$

Figure 4 shows the Fourier frequency spectral analysis (FFSA) of pressure disturbance at different surface locations under freestream pulse wave with $f=0.25$. The following is found. (a) The FFSA amplitude decreases sharply when $s$ is increasing from 0.91485 to about 3.71217. The FFSA amplitude increases continuously when $s$ is increasing from about 5.18153 to 9.10146 ; it is believed that the increasing is caused by the complex interference between the induced wave and boundary layer. This demonstrates that although the above-mentioned amplification caused by bow shock wave decreases sharply when $s$ is increasing from 0.91485 to about 3.71217 , the attenuation of the bow wave no longer plays a main role in the development of the amplitude of pressure disturbance. (b) In the nose boundary layer, the disturbance modes of $f<0.5$ (dimensionless frequency, same as mentioned below) are the major component of total disturbance modes. The nose boundary layer is dominated by low frequency with $f<0.5$. The Fourier amplitude of pressure disturbance mode with the frequency of less than fundamental modes $(f<0.25)$ reduces rapidly. As disturbance wave propagates from upstream to downstream direction (when $s>2.05003$ ), the FFSA amplitude for $f<0.25$ reduces slowly, while the disturbance modes with the frequency larger than 0.5 , in general, increase rapidly. (c) Five main disturbance clusters exist in the boundary layer at $s=2.05003$. The number of main disturbance clusters decreases from 3 to 2 when $s$ is increasing from 3.71217 to about $s=7.48985$. This indicates that the number of main disturbance clusters decreases with increasing of $s$. It should be noted that although the current study of hypersonic boundary layer on the free flow pulse is less, there are scholars that did a systematic numerical study or made theoretical values on hypersonic boundary layer flow stability characteristics. Liang $[18,34]$ studied the stabilities of hypersonic boundary layer over a 7-degree half-coneangle blunt cone under continuous small disturbance waves using both direct numerical simulation (DNS) and linear stability theory (LST) analysis. In the result, the boundary layer disturbance wave gets narrow with the evolution of the disturbance wave from the upstream boundary to the downstream boundary layer, and they thought this was presumably because of the boundary layer mode competition between different disturbance waves. According to the stability theory and the numerical study in literatures [34, 37], it is also believed that there is the existence of competition between different disturbances modes in the boundary layer, and their results also show that the frequency band of the disturbance wave in boundary layer along the streamwise would be narrowed. Literature [38] also got similar results. According to the investigations on the response of hypersonic boundary layer to continuous small disturbance, we tend to maintain that the reduction of the number of main disturbance clusters along the streamwise is mainly a consequence of the mode competition in boundary layer. (d) The frequency band narrows around the fundamental and the third harmonic mode sharply along the streamwise. The modes in boundary layer with different frequencies present various development trends along streamwise, for instance, first growth and then stability, continuous growth, and first decay and then stability. The dominant mode in boundary layer is transformed at one time near $s=7.48985$. These demonstrate that there is competition between different modes. Figure 5 shows the FFSA of pressure disturbance at different surface locations under freestream continuous wave with $f=0.25$. From Figures 4 and 5, it is found that the FFSA amplitude for continuous wave is far larger than that for pulse wave. This is due to the fact that the disturbance energy for continuous wave is persistent, while the time of energy excitement for pulse wave is ephemeral, which indicates the development of unstable wave in boundary layer under freestream pulse wave differs greatly from that under freestream continuous wave. From Figures 4 and 5, it also can be seen that, under the continuous wave with single frequency, the disturbance modes near the fundamental frequency and harmonics in boundary layer are mainly disturbance modes and the other modes can be insignificant; under the pulse wave with single frequency, the disturbance modes in boundary layer are found widely. This demonstrates that the disturbance energy of both the fundamental mode and harmonics is transferred to the other modes $\left(P_{n}, n\right.$ is not an integer), which makes the FFSA amplitude of the other modes increase. Therefore, the disturbance energy in boundary layer under pulse wave is divided, which makes the FFSA amplitude of the fundamental and harmonic modes in boundary layer decrease, and 

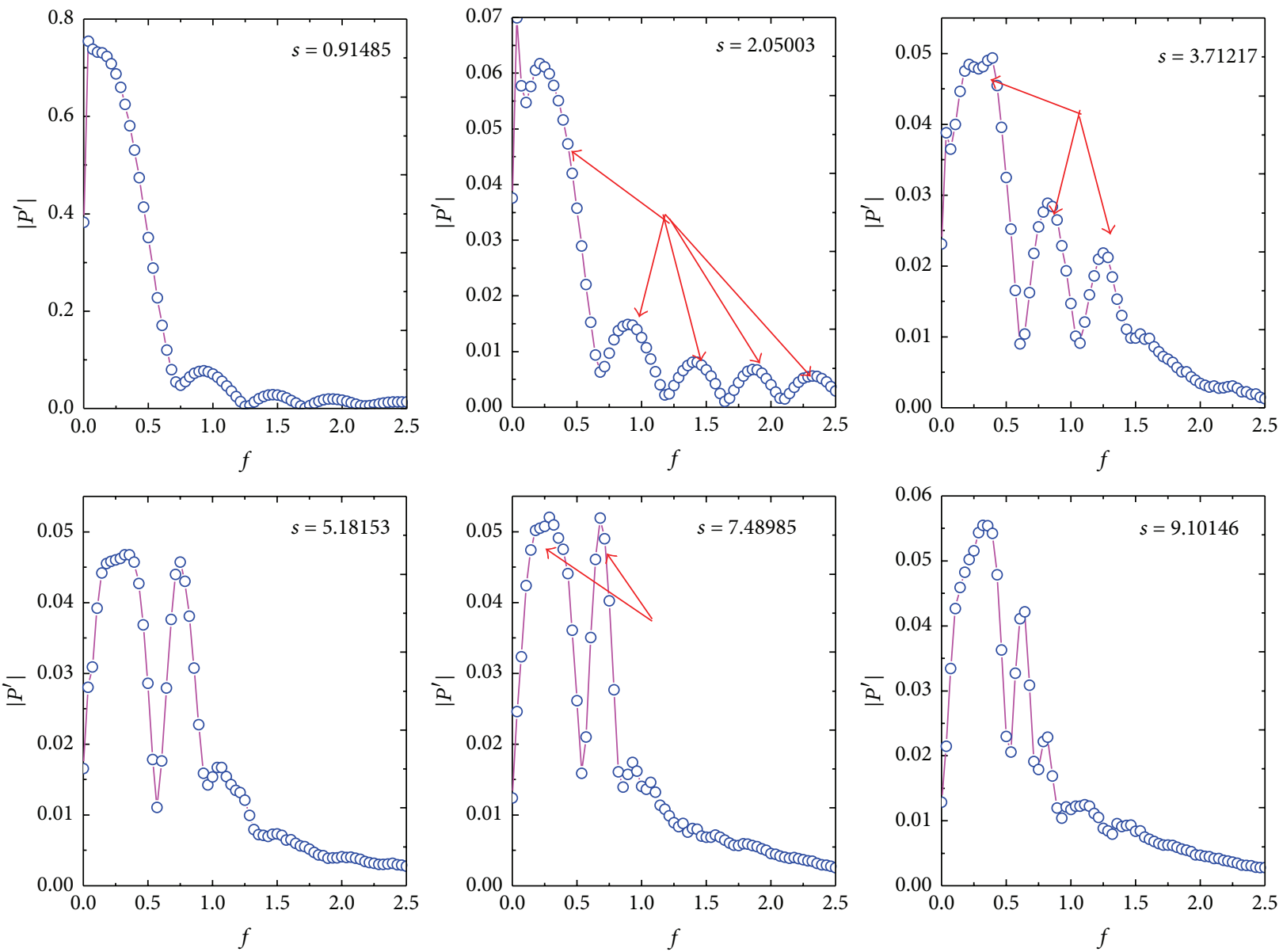

FIGURE 4: Fourier frequency spectral analysis of pressure disturbance in boundary layer for different locations under freestream pulse wave with $f=0.25\left(T_{W}=500 \mathrm{~K}\right)$.
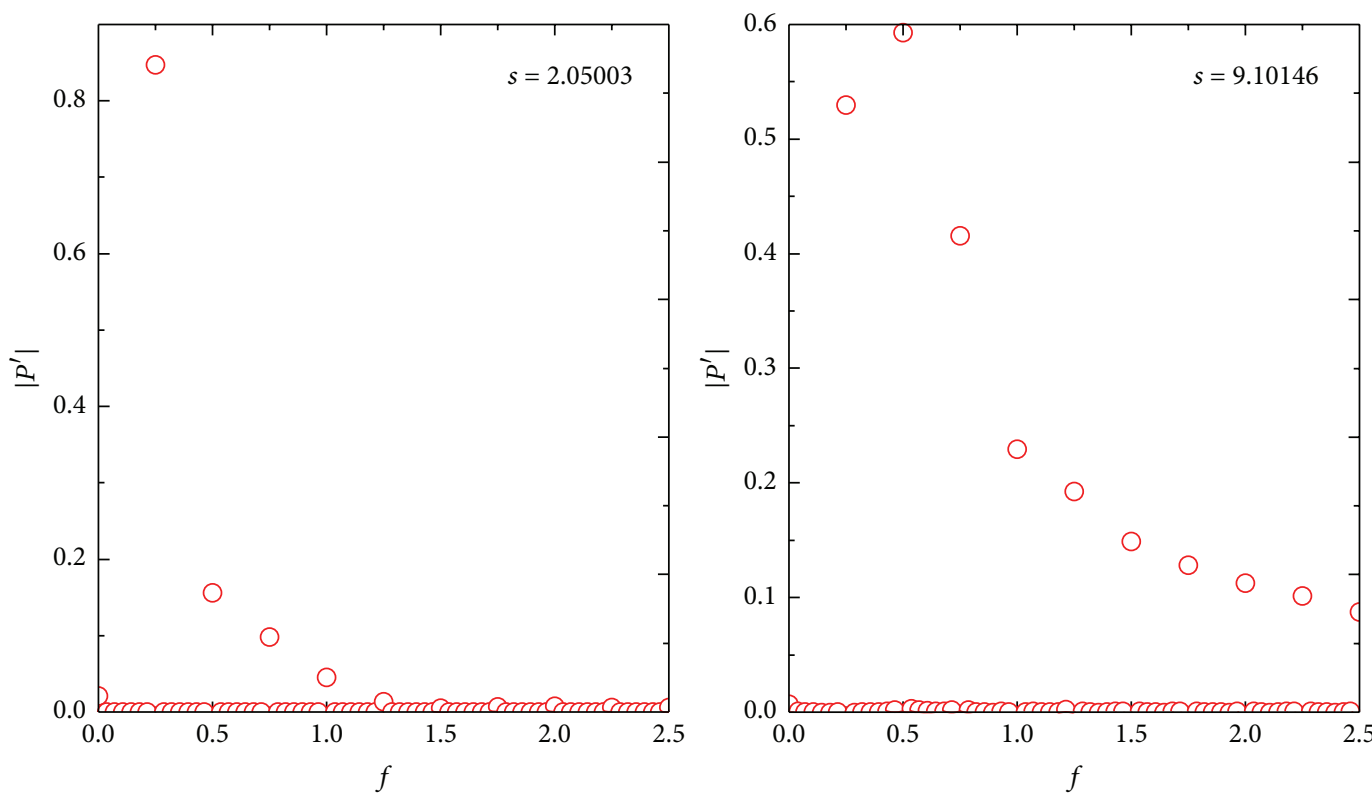

FIGURE 5: Fourier frequency spectral analysis of pressure disturbance in boundary layer for different locations under freestream continuous wave with $f=0.25\left(T_{W}=500 \mathrm{~K}\right)$. 


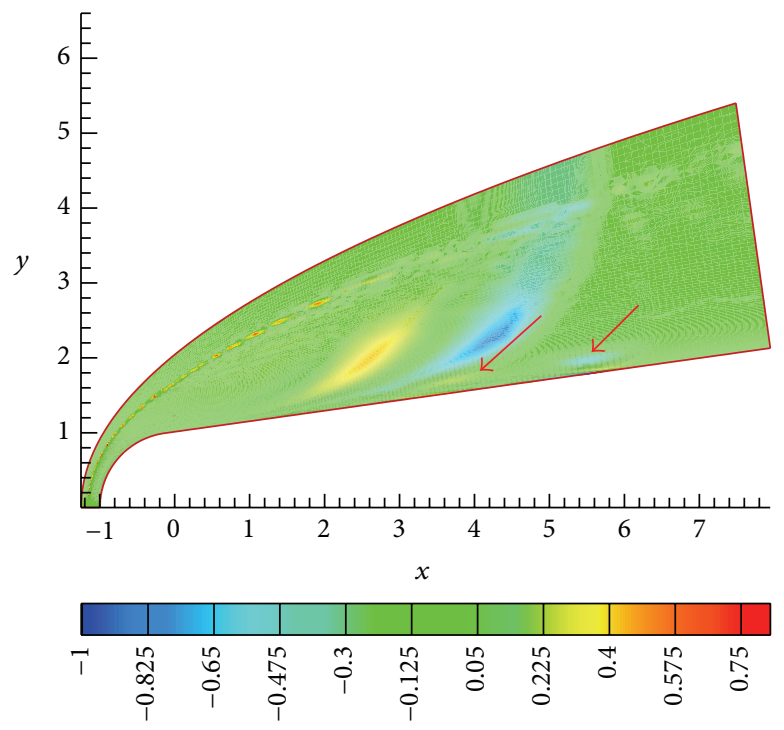

(a)

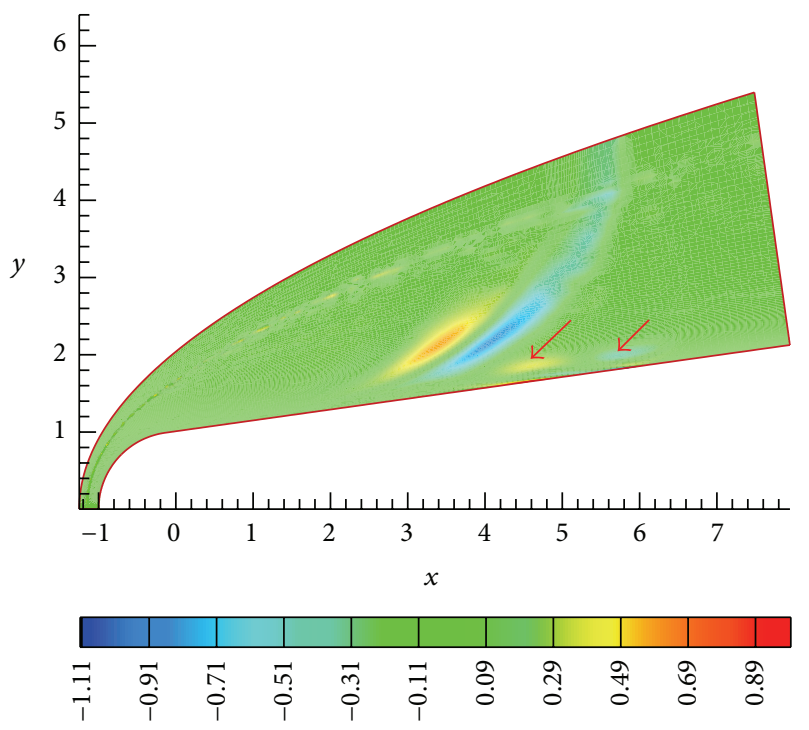

(b)

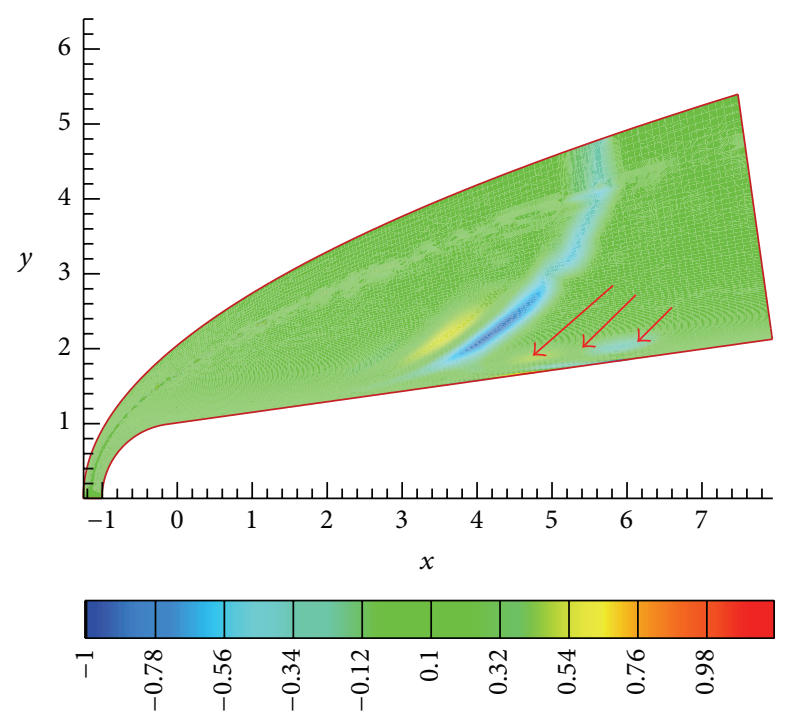

(c)

FiguRE 6: Contours of entropy disturbance $\operatorname{En}^{\prime}(x, y, t)$ for freestream pulse wave with different frequencies.

also is one important reason for the FFSA amplitude for pulse wave is less than that for continuous wave. Thus, it has been verified that the receptivity characteristics of boundary layer under freestream pulse wave differ greatly from that under continuous wave. The principal problem which is concerned by receptivity investigation is how the initial disturbances enter the boundary layer and the production and evolution of unstable disturbance wave, which plays an important role in determining the stability characteristics of boundary layer and transition location. In recent years, some researches focusing on the frequency effects of freestream continuous disturbance on receptivity are conducted and found that the frequency has significant influence on hypersonic boundary layer receptivity [19]. However, the effects of freestream continuous wave vary significantly compared with that of freestream pulse wave. Since systematic investigation is still rare in this area, it is necessary to investigate the frequency effects of pulse disturbance in freestream on hypersonic boundary layer receptivity. Therefore, the frequency effects of pulse disturbance in freestream will be discussed in Figures 6 to 10 .

4.2. Effects of Disturbance Frequency in Freestream. Contours of entropy disturbance $\operatorname{En}^{\prime}(x, y, t)$ for freestream pulse wave with different frequencies are shown in Figures 6(a)-6(c). Figures 6(a), 6(b), and 6(c) correspond to $f=0.25,0.50$, and 0.75 , respectively. The figure shows the entropy disturbance changed sharply both inside and outside boundary layer, showing that the thermodynamic characteristic of hypersonic flowfield is affected by freestream fast acoustic pulse wave. 

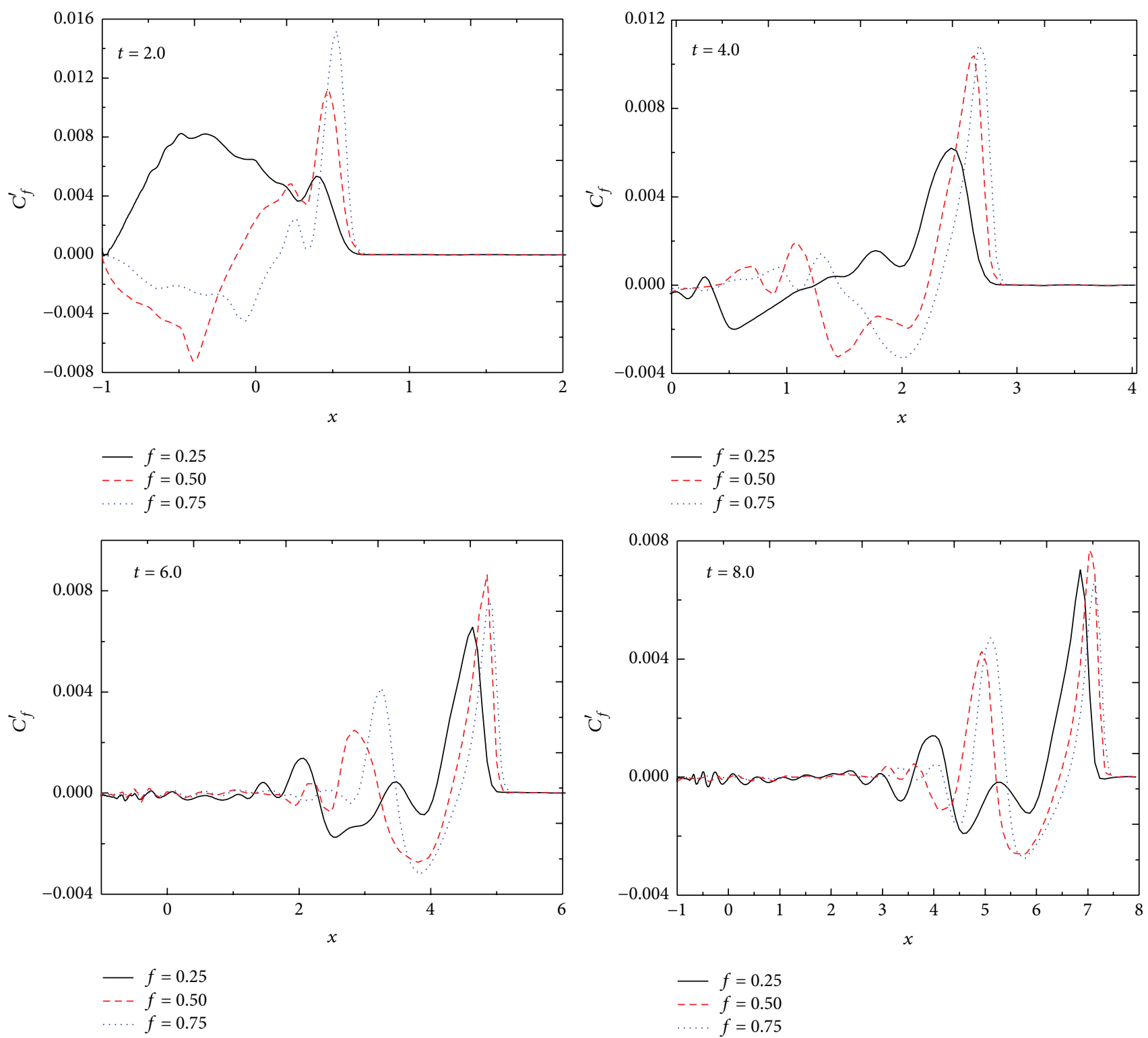

FIGURE 7: Comparison of friction factor disturbance distribution on wall at different times for different disturbance frequencies in freestream.

It also can be seen that the effect on the thermodynamic characters varies with the frequency of freestream disturbance. The thermodynamic character of hypersonic flowfield, particularly that of boundary layer, plays an important role in the unstable wave evolution and boundary layer stability [1, $27,28]$. Therefore, it can be believed that various tends will be revealed for the disturbance wave evolution in boundary layer along streamwise under different freestream disturbance frequencies, which makes the difference of boundary layer stability and transition location under freestream disturbance with different frequencies.

Distributions of friction factor disturbance $C_{f}^{\prime}(x, y, t)$ for freestream pulse wave with different frequencies at different times $(t=2.0,4.0,6.0$, and 8.0) are shown in Figure 7. It shows the same tends will be revealed for the friction factor wave under freestream disturbance with different frequencies. However, there is significant difference between different freestream disturbances with different frequencies. Since the friction factor is the characteristic variable for strong shear flow, the structure of strong shear flow in boundary layer is changed due to the change of the friction factor. The influence of shear stress along wall surface on boundary was investigated in Hirschel's work and found that the state of boundary layer is affected by the characteristics of wall shear stress. Therefore, the effects of freestream pulse wave frequency on the evolvement of unstable disturbance waves in boundary layer will be analyzed in Figures 8 to 10 .

Figure 8 shows the comparison of Fourier frequency spectral analysis of pressure disturbance in boundary layer at different locations for different disturbance frequencies in freestream. The evolution of disturbance wave in boundary 

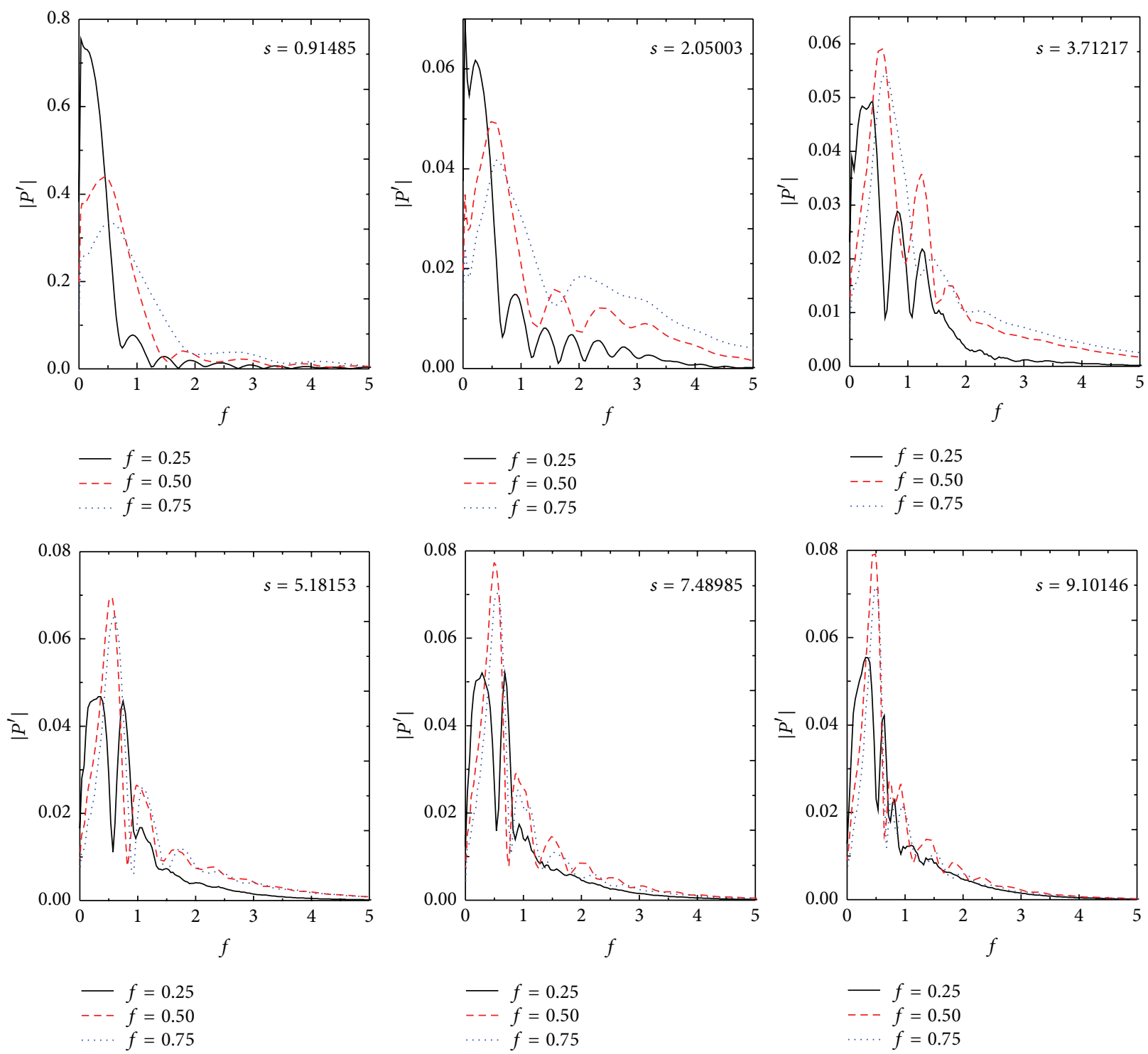

FIGURE 8: Comparison of Fourier frequency spectral analysis of pressure disturbance in boundary layer at different locations for different disturbance frequencies in freestream.

layer along streamwise can be seen. As is seen in the figure, (a) when $f<0.25\left(f<f_{1}\right)$, the FFSA amplitude increases with increasing disturbance frequency in freestream; however, when $f>1.0$, the trend is reversed. When 0.5 $<f<1.0$, the amplitude for freestream disturbance with frequency $f=0.5, f=0.75$, and $f=0.25$ sequence has a small increase. For the 3 freestream disturbance waves, after the attenuation of low frequency and the increase of high frequency component upstream, most modes components attenuate, and the frequency band narrows around the dominant mode along the streamwise. (b) After the disturbance entering boundary layer, disturbance waves with different frequencies will be induced; it has been verified that, as discussed earlier, there will appear several main disturbance mode clusters in boundary layer. It is found that the number of main disturbance mode clusters decreases with increasing of freestream disturbance frequency. (c) It is also found that the maximal amplitude of FFSA in boundary layer increases with decreasing of freestream disturbance frequency upstream. However, with the development of disturbance wave from upstream to downstream direction, the case for low frequency disturbance in freestream has smaller maximal amplitude of FFSA. It shows a similar trend for the evolution of disturbance wave in boundary layer along streamwise under freestream disturbance with different frequencies. However, freestream disturbances frequency has significant effects on disturbance wave evolution in boundary layer.

Figure 9 shows the comparison of growth of different disturbance modes in boundary layer at different locations for freestream different disturbance frequencies. From Figure 9, the following is found. (a) When $s=0.92619$ (the nose 

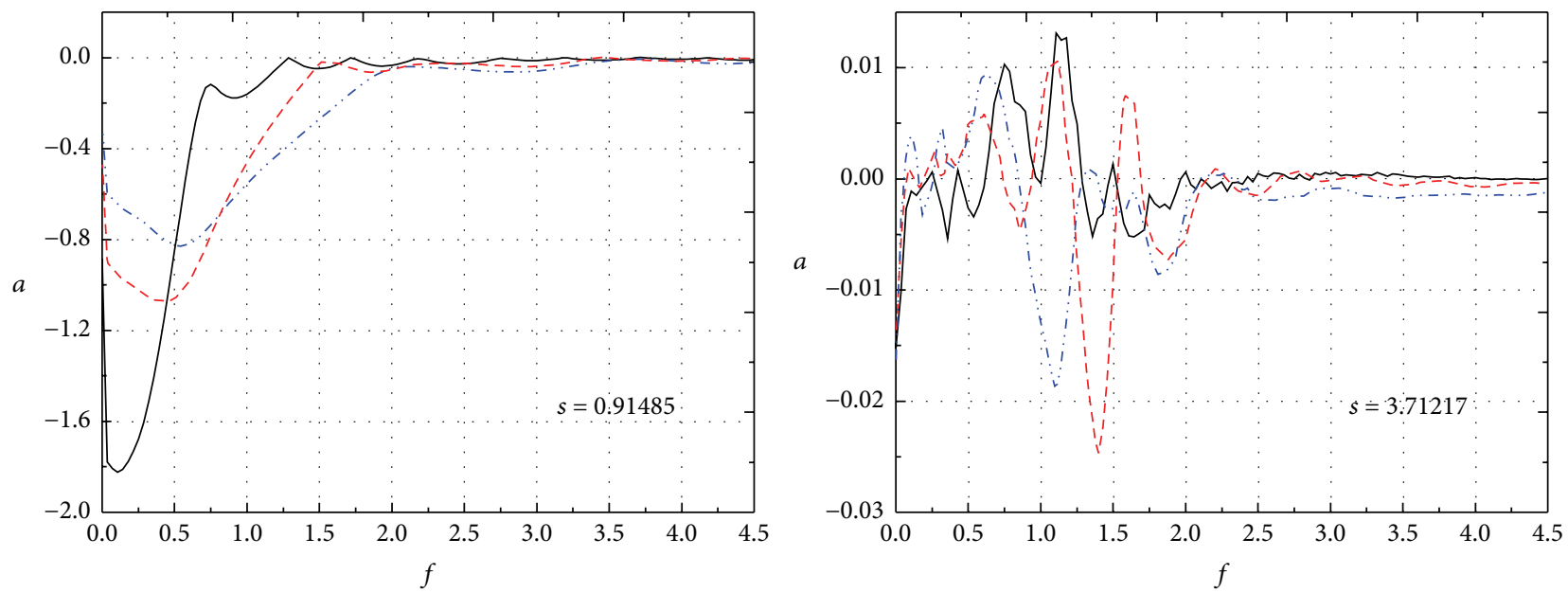

$$
\begin{aligned}
-f & =0.25 \\
---f & =0.50 \\
\cdots-f & =0.75
\end{aligned}
$$
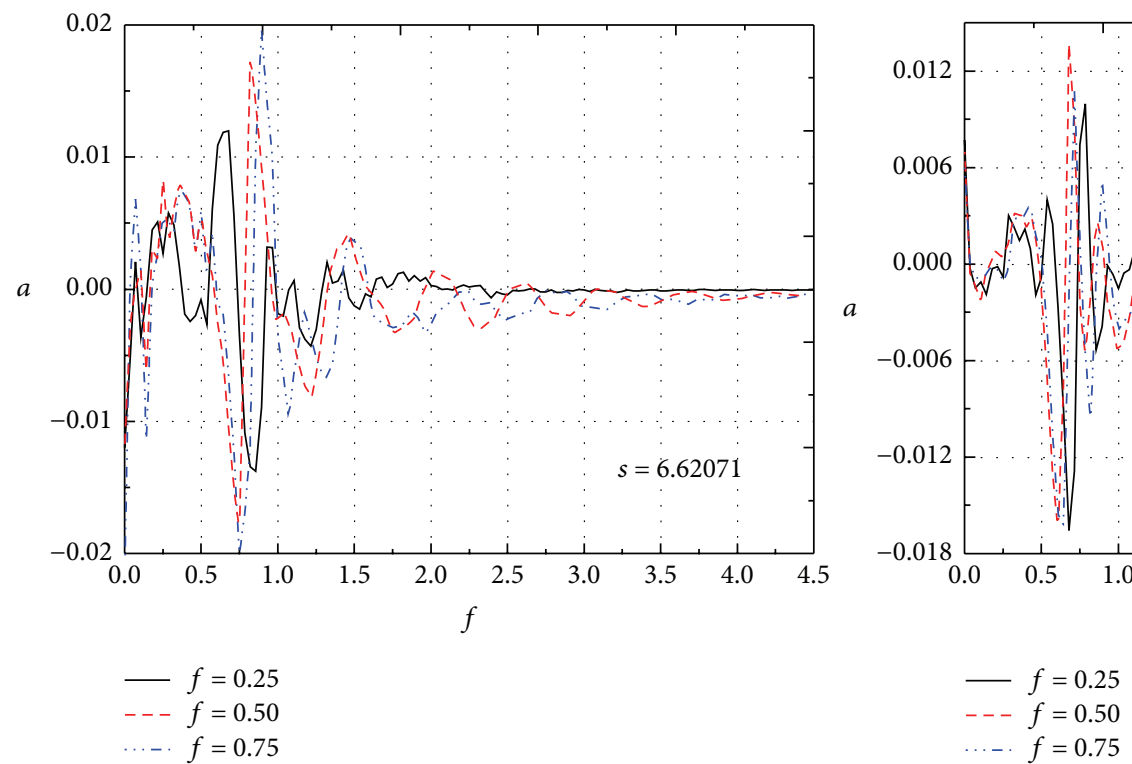

FIGURE 9: Comparison of growth of different disturbance modes in boundary layer at different locations for freestream different disturbance frequencies.

boundary layer), for the three-frequency disturbance in freestream, the FFSA amplitude of all modes in boundary layer decays sharply. When $f<0.5$, the decay of boundary layer disturbance wave becomes faster with decreasing disturbance frequency in freestream; however, when $f>0.75$, the trend is reversed. (b) Various tends are present for the same disturbance mode under freestream disturbance with different frequencies. It indicates the effects on disturbance wave development vary with freestream disturbance frequency. (c) The frequency range with larger growth narrows along the streamwise. When $s=9.28135$, the frequency range narrows into $0.5<f<1.0$.

Figure 10 shows the comparison of pressure disturbance modes $P_{1-4}$ under freestream disturbance with different frequencies. Similar tends are revealed for both fundamental mode and harmonics under freestream disturbance with different frequencies. In general, the amplitudes of both fundamental mode and harmonics become larger with the decreasing of freestream disturbance frequency. It should be mentioned that a similar result is obtained by Liang et al. in the investigation on the receptivity of hypersonic boundary layer to freestream continuous small disturbance [18]. Owing to the fact that the bow shock wave goes from normal shock wave in nose region to oblique shock wave in nonnose region, there is a sharp decay for both fundamental mode and harmonics. The decay becomes faster with decreasing disturbance frequency in freestream. The amplitude of the third harmonic mode $P_{3}$ near $s=2.0$ 

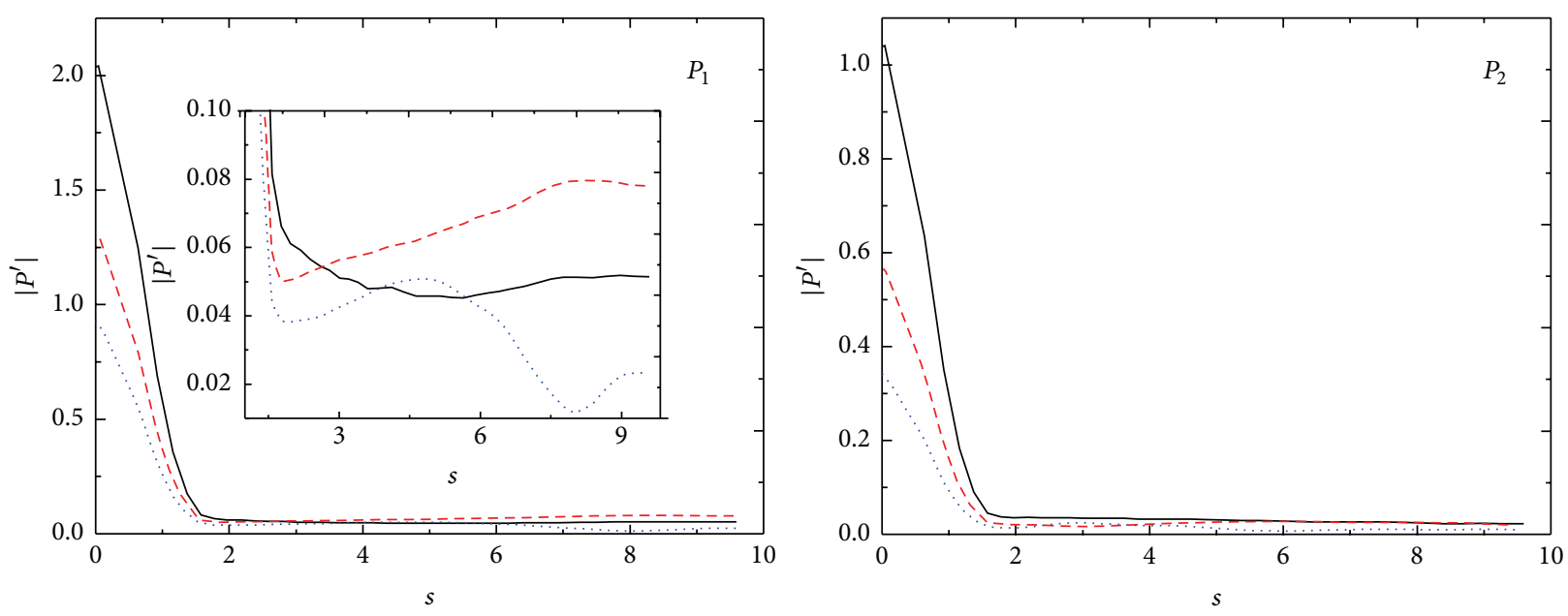

$$
\begin{aligned}
-f & =0.25 \\
---f & =0.50 \\
\cdots \cdots f & =0.75
\end{aligned}
$$

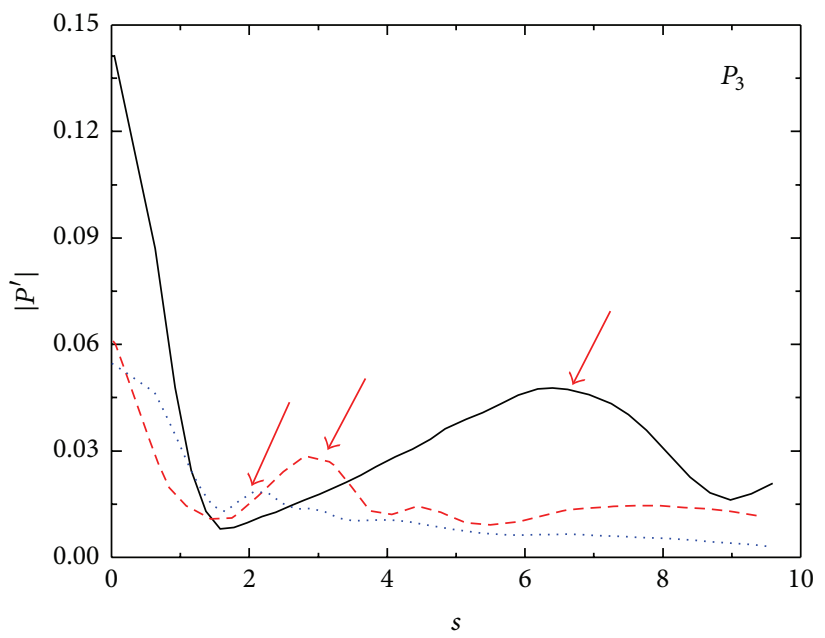

$$
\begin{aligned}
f & =0.25 \\
---f & =0.50 \\
\cdots \cdots f & =0.75
\end{aligned}
$$

$$
\begin{aligned}
-f & =0.25 \\
---f & =0.50 \\
\cdots \cdots f & =0.75
\end{aligned}
$$

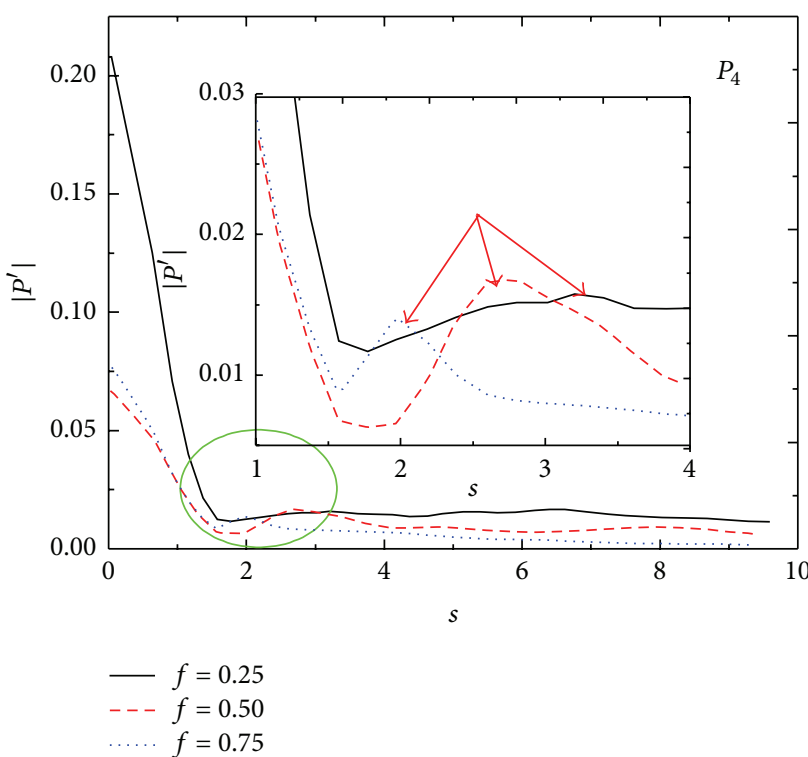

FIgURE 10: Comparison of pressure disturbance modes for different disturbance frequencies in freestream.

for freestream disturbance frequency $f=0.25$ is even smaller than that for both freestream disturbance frequencies $f=0.5$ and $f=0.75$ at one time. After the amplitudes of $P_{n}$ increase, due to the flow being recompressed at the back of the junction region between the spherical nose and the straight cone, the amplitudes of $P_{n}$ will decay along the streamwise in the nonnose boundary layer. High freestream disturbance frequency accelerates the decay of disturbance wave in downstream boundary layer, as the arrow is shown in Figure 10. A similar result is obtained by Zhang et al. in the investigation on the stability of hypersonic boundary layer over a blunt cone under freestream continuous small disturbance blended with different frequencies [19]. In general, freestream disturbances frequency has significant effects on disturbance wave evolution in boundary layer which plays an important role in determining the stability of hypersonic boundary layer and laminar-turbulent transition location.

\section{Conclusion}

The receptivity of boundary layer to freestream pulse acoustic wave is analyzed, and the effects of freestream pulse wave frequency on the receptivity characteristics of boundary layer are investigated. Some conclusions are obtained.

(a) Under freestream fast acoustic pulse disturbance, the thermodynamic characteristic of shear flow is sharply changed in boundary layer. Bow shock wave has a significant amplification effect on freestream disturbance wave. The amplification effect no longer 
plays a main role in the developing of the amplitude of disturbance wave in boundary layer away from the nose.

(b) There are several main disturbance mode clusters in boundary layer under freestream pulse wave, and the number of main disturbance clusters decreases along the streamwise. The nearby mode of fundamental frequency is dominant mode in the nose boundary layer. As disturbance wave propagates from upstream to downstream direction, the ratio of low frequency (less than fundamental mode) component decreases, and the ratio of the high frequency (larger than the second harmonic mode) components increases quickly in total disturbance modes. There is competition and disturbance energy transfer between different modes in boundary layer.

(c) Freestream disturbance frequency has a significant effect on the structure of shear flow, the thermodynamic characteristic of boundary layer, and the disturbance wave evolution in boundary layer. When the disturbance frequency in boundary layer is low $(f<$ $f_{1}$ ), the FFSA amplitude increases with increasing disturbance frequency in freestream; however, when the frequency is high $\left(f>f_{4}\right)$, the trend is reversed. The number of main disturbance mode clusters decreases with increasing of freestream disturbance frequency. For the three-frequency disturbance in freestream, all modes in the nose boundary layer decay sharply. When the disturbance frequency in boundary layer is low ( $f<f_{2}$ ), the decay of disturbance wave becomes faster with decreasing disturbance frequency in freestream; however, when the frequency is high $\left(f>f_{3}\right)$, the trend is reversed. The frequency range with larger growth narrows along the streamwise. In general, the amplitudes of both fundamental mode and harmonics become larger with the decreasing of freestream disturbance frequency. High freestream disturbance frequency accelerates the decay of disturbance wave in downstream boundary layer.

\section{Competing Interests}

The authors declare that they have no competing interests.

\section{Acknowledgments}

This work was supported by the National Natural Science Funds (11272096), the Ph.D. Programs Foundation of Ministry of Education of China (20112304110015), and the Fundamental Research Funds for the Central Universities (HEUCF130216).

\section{References}

[1] W. Hayes, Hypersonic Flow Theory, Elsevier, San Diego, Calif, USA, 2012.
[2] O. Yemenici, Z. A. Firatoglu, and H. Umur, "An experimental investigation of flow and heat transfer characteristics over blocked surfaces in laminar and turbulent flows," International Journal of Heat and Mass Transfer, vol. 55, no. 13-14, pp. 36413649, 2012.

[3] X. Zhong and X. Wang, "Direct numerical simulation on the receptivity, instability, and transition of hypersonic boundary layers," Annual Review of Fluid Mechanics, vol. 44, pp. 527-561, 2012.

[4] O. Guès, G. Métivier, M. Williams, and K. Zumbrun, "Existence and stability of noncharacteristic boundary layers for the compressible Navier-Stokes and viscous MHD equations," Archive for Rational Mechanics and Analysis, vol. 197, no. 1, pp. 1-87, 2010.

[5] W.-L. Jia and W. Cao, "The effects of variable specific heat on the stability of hypersonic boundary layer on a flat plate," Applied Mathematics and Mechanics, vol. 31, no. 8, pp. 979-986, 2010.

[6] S. Ukai, T. Yang, and S. H. Yu, "Nonlinear stability of boundary layers of the Boltzmann equation, I. The case $\mathscr{M}^{\infty}<-1$," Communications in Mathematical Physics, vol. 244, no. 1, pp. 99109, 2004.

[7] F. Huang and X. Qin, "Stability of boundary layer and rarefaction wave to an outflow problem for compressible NavierStokes equations under large perturbation," Journal of Differential Equations, vol. 246, no. 10, pp. 4077-4096, 2009.

[8] M. R. Malik, "Numerical methods for hypersonic boundary layer stability," Journal of Computational Physics, vol. 86, no. 2, pp. 376-413, 1990.

[9] J. P. Hughes and D. I. Graham, "Comparison of incompressible and weakly-compressible SPH models for free-surface water flows," Journal of Hydraulic Research, vol. 48, supplement 1, pp. 105-117, 2010.

[10] E.-S. Lee, C. Moulinec, R. Xu, D. Violeau, D. Laurence, and P. Stansby, "Comparisons of weakly compressible and truly incompressible algorithms for the SPH mesh free particle method," Journal of Computational Physics, vol. 227, no. 18, pp. 8417-8436, 2008.

[11] A. Fedorov, A. Shiplyuk, A. Maslov, E. Burov, and N. Malmuth, "Stabilization of a hypersonic boundary layer using an ultrasonically absorptive coating," Journal of Fluid Mechanics, vol. 479, pp. 99-124, 2003.

[12] A. V. Fedorov and A. P. Khokhlov, "Excitation of unstable modes in a supersonic boundary layer by acoustic waves," Fluid Dynamics, vol. 26, no. 4, pp. 531-537, 1991.

[13] Y. Ma and X. Zhong, "Receptivity of a supersonic boundary layer over a flat plate. Part 3. Effects of different types of freestream disturbances," Journal of Fluid Mechanics, vol. 532, pp. 63-109, 2005.

[14] G. C. Layek, C. Midya, and S. Mukhopadhyay, "Effects of suction and blowing on flow separation in a symmetric sudden expanded channel," Nonlinear Analysis: Modelling and Control, vol. 13, no. 4, pp. 451-465, 2008.

[15] K. Kara, P. Balakumar, and O. A. Kandil, "Effects of nose bluntness on hypersonic boundary-layer receptivity and stability over cones," AIAA Journal, vol. 49, no. 12, pp. 2593-2606, 2011.

[16] J. Lee, S. Yoon Jung, H. Jin Sung, and T. A. Zaki, "Effect of wall heating on turbulent boundary layers with temperaturedependent viscosity," Journal of Fluid Mechanics, vol. 726, pp. 196-225, 2013.

[17] P.-Å. Krogstad and R. A. Antonia, "Surface roughness effects in turbulent boundary layers," Experiments in Fluids, vol. 27, no. 5, pp. 450-460, 1999. 
[18] X. Liang, X. Li, D. Fu, and Y. Ma, "Effects of wall temperature on boundary layer stability over a blunt cone at Mach 7.99," Computers and Fluids, vol. 39, no. 2, pp. 359-371, 2010.

[19] Y. D. Zhang, D. X. Fu, Y. W. Ma, and X. Li, "Receptivity to free-stream disturbance waves for hypersonic flow over a blunt cone," Science in China. Series G: Physics, Mechanics and Astronomy, vol. 51, no. 11, pp. 1682-1690, 2008.

[20] A. Barrow, S. J. Garrett, and N. Peake, "Global linear stability of the boundary-layer flow over a rotating sphere," European Journal of Mechanics B. Fluids, vol. 49, pp. 301-307, 2015.

[21] E. Appelquist, S. Imayama, P. H. Alfredsson, P. Schlatter, and R. J. Lingwood, "Linear disturbances in the rotating-disk flow: a comparison between results from simulations, experiments and theory," European Journal of Mechanics-B/Fluids, vol. 55, part 1, pp. 170-181, 2016.

[22] V. Citro, P. Luchini, F. Giannetti et al., "Boundary-layer flows past an hemispherical roughness element: DNS, global stability and sensitivity analysis," Procedia IUTAM, vol. 14, pp. 173-181, 2015.

[23] J. L. Steger and R. F. Warming, "Flux vector splitting of the inviscid gasdynamic equations with application to finitedifference methods," Journal of Computational Physics, vol. 40, no. 2, pp. 263-293, 1981.

[24] X.-D. Liu, S. Osher, and T. Chan, "Weighted essentially nonoscillatory schemes," Journal of Computational Physics, vol. 115, no. 1, pp. 200-212, 1994.

[25] P. Balakumar and L. R. Owens, "Stability of hypersonic boundary layers on a cone at an angle of attack," AIAA Paper 4718: 2010, 2010.

[26] C. W. Shu, "Essentially non-oscillatory and weighted essentially non-oscillatory schemes for hyperbolic conservation laws," in Advanced Numerical Approximation of Nonlinear Hyperbolic Equations, pp. 325-432, Springer, Berlin, Germany, 1998.

[27] P. Balakumar, "Receptivity of supersonic boundary layers to acoustic disturbances over blunt cones," in Proceedings of the 37th AIAA Fluid Dynamics Conference and Exhibit, AIAA Paper 2007-4491, pp. 1-24, Miami, Fla, USA, June 2007.

[28] K. Kara, P. Balakumar, and O. A. Kandil, "Receptivity of hypersonic boundary layers due to acoustic disturbances over blunt cones," in Proceedings of the 37th AIAA Fluid Dynamics Conference and Exhibit, pp. 11464-11481, Miami, Fla, USA, January 2007.

[29] I. V. Egorov, A. V. Fedorov, and V. G. Soudakov, "Direct numerical simulation of disturbances generated by periodic suction-blowing in a hypersonic boundary layer," Theoretical and Computational Fluid Dynamics, vol. 20, no. 1, pp. 41-54, 2006.

[30] A. J. Laderman, "Effect of wall temperature on a supersonic turbulent boundary layer," AIAA Journal, vol. 16, no. 7, pp. 723729,1978 .

[31] K. F. Stetson, "Hypersonic boundary layer transition experiments," Tech. Rep. AFWAL-TR-80-3062, Air Force Wright Aeronautical Labs, Wright-Patterson AFB, Ohio, USA, 1980.

[32] X. Wang, X. Zhong, and Y. Ma, "Response of a hypersonic boundary layer to wall blowing-suction," AIAA Journal, vol. 49, no. 7, pp. 1336-1353, 2011.

[33] X. J. Yuan, G. H. Tu, H. X. Zhang, and Q. Shen, "The effect between the boundary layer shock wave and the disturbance waves," Journal of Aerodynamics, vol. 1, pp. 22-27, 2006.

[34] X. Liang, Hypersonic Blunt Cone Boundary Layer Stability Characteristics, Shanghai University, 2010.
[35] J. S. Yan, The Boundary Layer Stability Analysis and Transition Forecasting of the Hypersonic Blunt Cone at Zero Angle of Attack, Tianjin University, 2009.

[36] Z. Wang, X. Tang, H. Lv, and J. Shi, “Temporal and spatial evolution characteristics of disturbance wave in a hypersonic boundary layer due to single-frequency entropy disturbance," The Scientific World Journal, vol. 2014, Article ID 517242, 14 pages, 2014.

[37] A. Tumin, X. Wang, and X. Zhong, "Numerical simulation and theoretical analysis of perturbations in hypersonic boundary layers," AIAA Journal, vol. 49, no. 3, pp. 463-471, 2011.

[38] C. H. Pua, S. F. Norizan, S. W. Harun, and H. Ahmad, "Nonmembrane optical microphone based on longitudinal modes competition," Sensors and Actuators A: Physical, vol. 168, no. 2, pp. 281-285, 2011. 


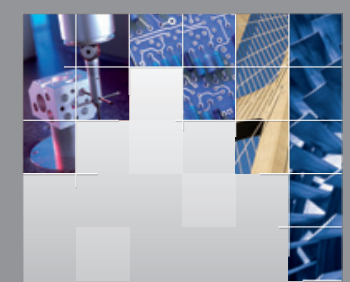

\section{Enfincering}
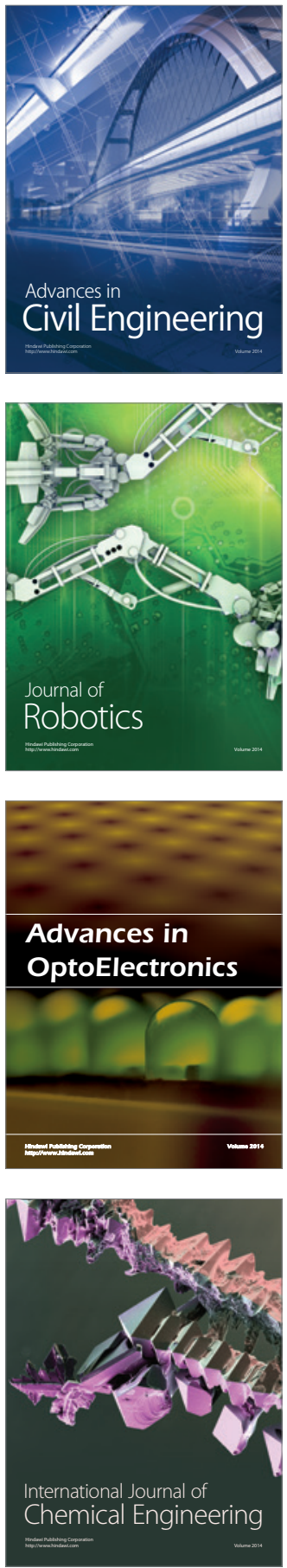

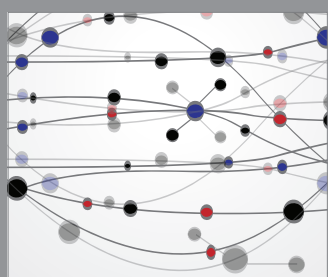

The Scientific World Journal

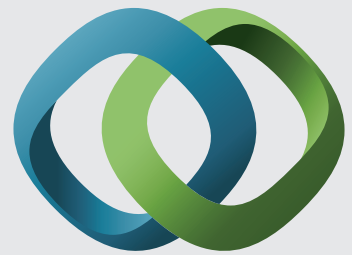

\section{Hindawi}

Submit your manuscripts at

http://www.hindawi.com
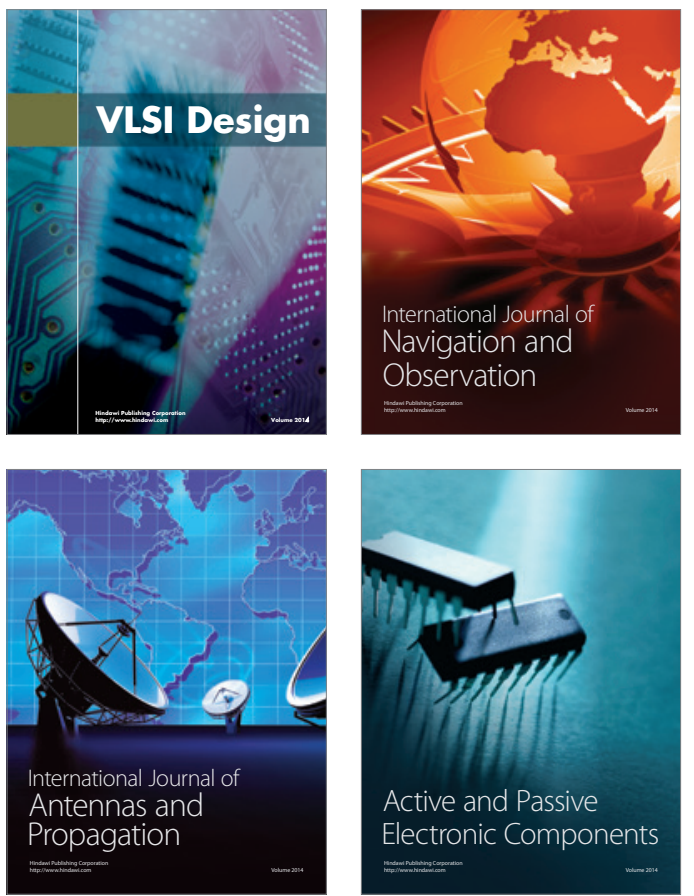
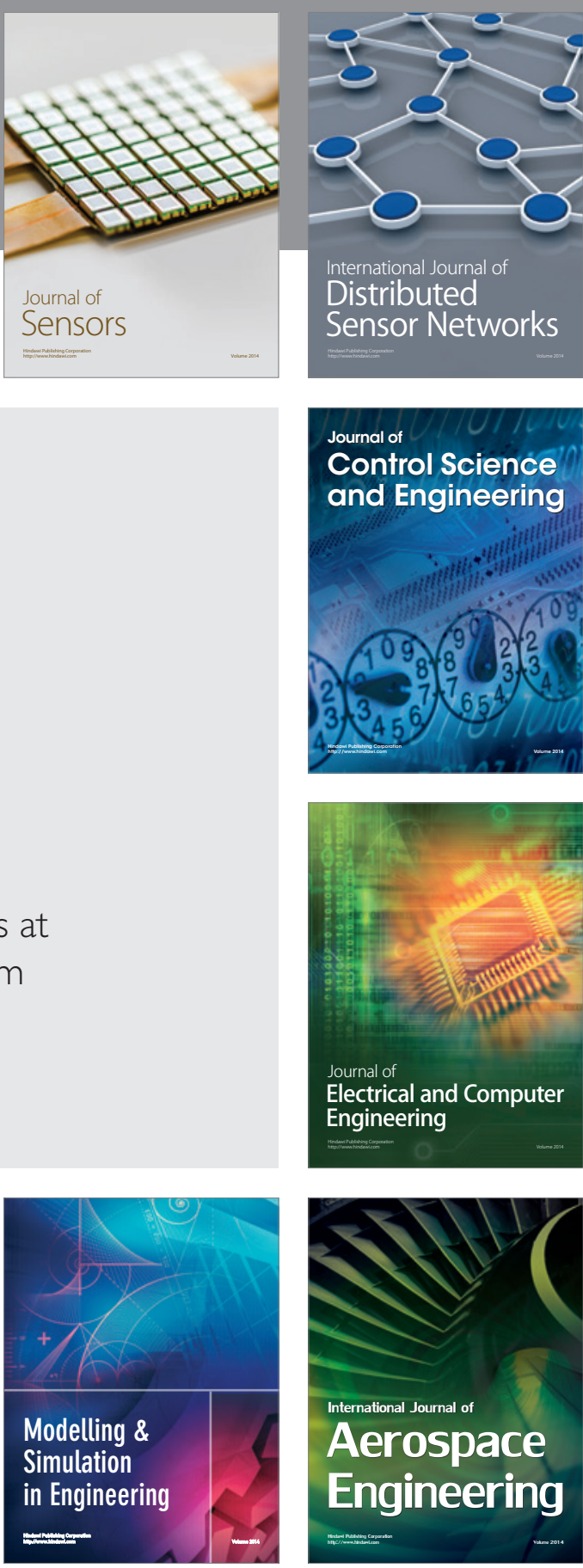

International Journal of

Distributed

Sensor Networks

Journal of

Control Science

and Engineering
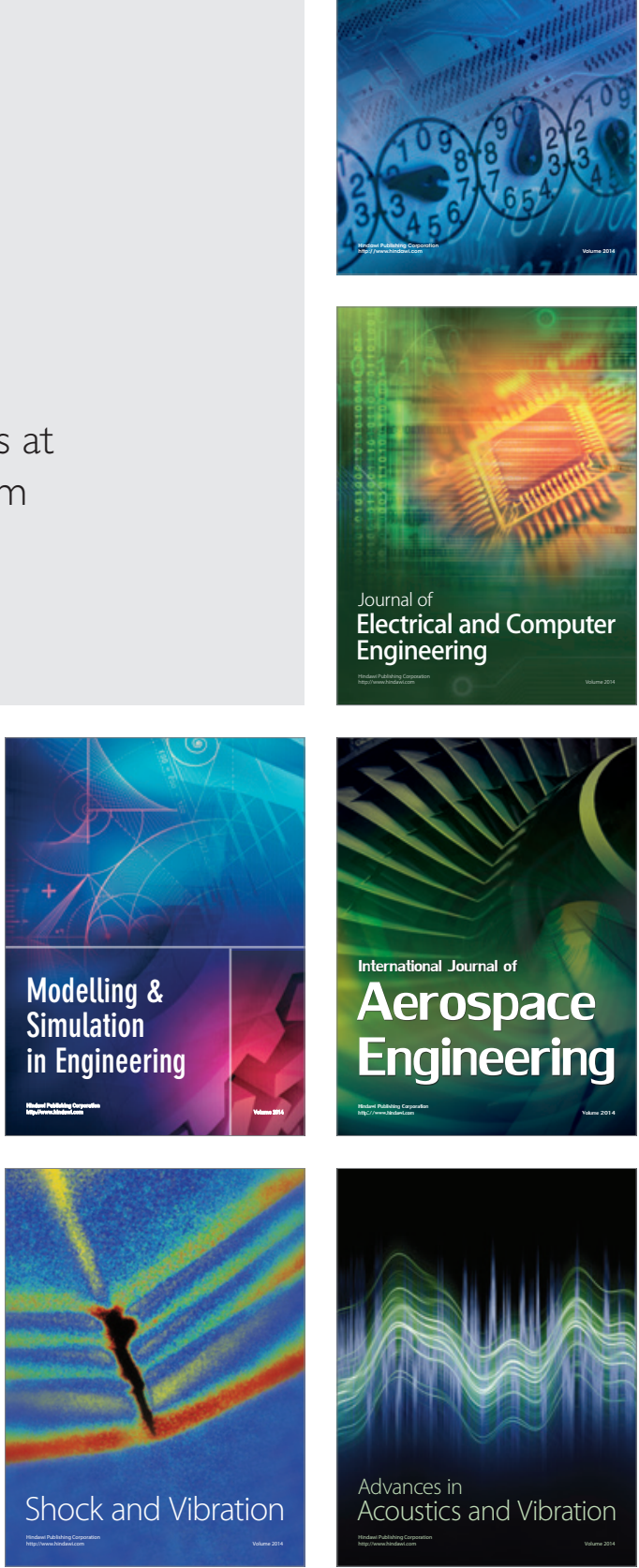